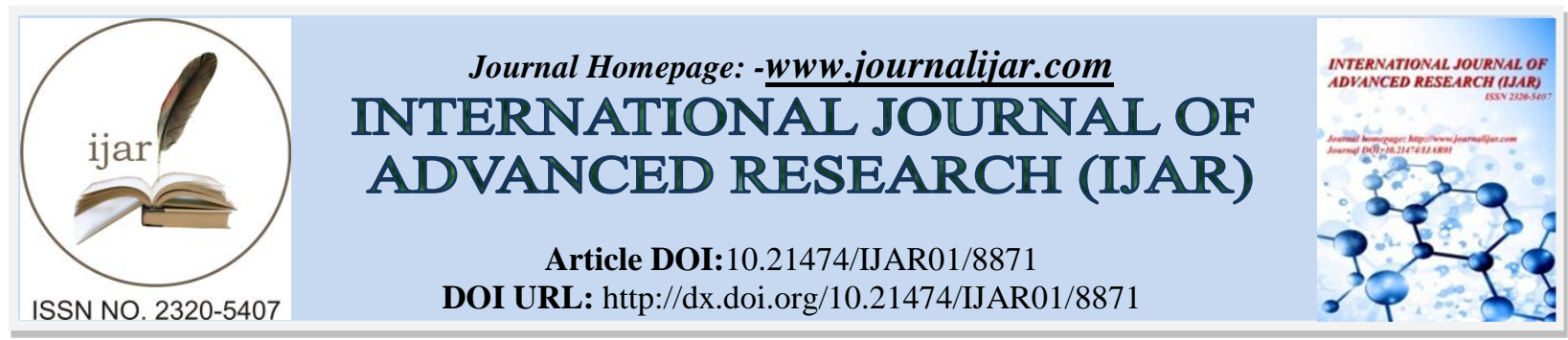

RESEARCH ARTICLE

\title{
MOLECULAR CHARACTERIZATION OF LACTIC ACID BACTERIA ISOLATED FROM BURNT SWEET CHEESE (CHHENAPODA).
}

\author{
Soumya Pragyan Das ${ }^{1}$ and Dr Prafulla Kumar Mohanty ${ }^{2}$. \\ 1. Research Scholar, P.G. Department of Zoology, Utkal University- 751004, Odisha, India. \\ 2. Professor, P.G. Department of Zoology, Utkal University- 751004, Odisha, India.
}

\section{Manuscript Info}

Manuscript History

Received: 10 February 2019

Final Accepted: 12 March 2019

Published: April 2019

Key words:-

Lactic acid bacteria, burnt sweet cheese, molecular characterization.

\begin{abstract}
The purpose of this study was to isolate and characterize lactic acid bacteria from fermented burnt sweet cheese (chhenapoda) by PCR based molecular methods for identification of the isolates, which may help to formulate the starter culture as well as in the biological preservation of foods. Both classical and PCR based molecular methods were used to identify the lactic acid bacteria isolates. A total number of 18 isolates have been recovered from chhenapoda and characterized with molecular tools. RAPD analysis was performed initially to cluster the isolates using two different primers $27 \mathrm{~F}$ and 1492R. Species identification was based on sequence analysis of 16SrRNA gene. A single cluster of lactic acid bacteria PCR products was sequenced and subjected to BLAST. The isolate showed high similarity with Bacillus vallismortis based on nucleotide homology and phylogenetic analysis. Phylogenetic analysis was performed using software MEGA 7. The study concludes that Bacillus vallismortis can be used to formulate starter cultures for the commercial production of burnt sweet cheese (chhenapoda), in dairy industries.
\end{abstract}

Copy Right, IJAR, 2019,. All rights reserved.

\section{Introduction:-}

Lactic acid bacteria (LAB) are candidate probiotic bacteria (Todorov and Franco, 2010) distributed widely in nature and used in food industry (Tserovska et al., 2010). Probiotic bacteria confer health benefits to the human gastrointestinal tract (Junior et al., 2015; Reale et al., 2015). LAB are a group of anaerobic or microaerophilic Grampositive bacteria, unable to form spores and catalase, characterized by the absence of the cytochrome system (Cintas et al., 2001; Lu et al., 2014) and able to produce antimicrobial substances for biopreservation (Tabanelli et al., 2014; Bozoudi et al., 2015). Mostly, dairy products such as yogurt and cheese are good sources of probiotics (Palomo et al., 2014). The advantages of lactic acid fermentation include improved shelf life and increased food palatability (Sullivan et al., 2002). Lactic acid bacteria are generally recognized as safe (GRAS) as they can produce bacteriocins and confer several health benefits such as controlling intestinal infections, improving lactose utilization, lowering blood ammonia levels, providing resistance against gastric acid and bile (Federici et al., 2014; Kumar and Kumar, 2015; Angmo et al., 2016), boosting immunity and lowering serum cholesterol levels (Ouwehand et al., 2002; Liong and Shah, 2005). Also, LAB `colonize the gastrointestinal tract providing pathogen inhibition (Giraffa, 2003; Mercenier et al., 2003). The presence of lactic acid bacteria has hardly any impact on other intestinal microbial groups (Stromptova and Laukova, 2014). Chhenapoda, a traditional dessert of Odisha, is literally known

Corresponding Author:-Soumya Pragyan Das.

Address:-Research Scholar, P.G. Department of Zoology, Utkal University- 751004, Odisha, India. 
as burnt sweet cheese. It is originated in the $20^{\text {th }}$ century in the Nayagarh district of Odisha, India by a person Sudarshana Sahoo by name. It is often offered to Lord Jagannath at the Sri Jagannath temple, Puri, Odisha. It is made up of well kneaded homemade cottage cheese, sugar, cashewnut and raisins. This rare dessert is baked for 5 hours until it becomes brownish red or of caramel colour. The caramelized sugar brings out the distinct flavour of chhenapoda. Its shelf life is usually 3 to 4 days. Being sold in almost every nook and corner of Odisha, this dish is simple, easy and absolutely delicious.

DNA based molecular identification of the 16SrRNA gene helps in discriminating between closely related bacterial species (Kargozari et al., 2015). The isolation, identification and characterization of the lactic acid bacteria help in finding the taxonomy of the isolate. Also, the beneficial and functional probiotic LAB is also obtained (Fuller, 1989; Bujnakova et al., 2014). There is hardly any research on the LAB present in chhenapoda or burnt sweet cheese. Therefore, the study aims at isolation, identification and molecular characterization of the lactic acid bacteria in order to develop a suitable starter culture for controlled fermentation.

\section{Materials And Methods:- Sample Collection:}

Fifty samples $(n=50)$ of burnt sweet cheese (chhenapoda) were collected from different regions of Odisha. Samples were packed in sterilized bags and transported to the laboratory for analysis.

\section{Isolation of the lactic acid bacteria:}

Lactic acid bacteria were isolated from chhenapoda sample using de Man, Rogosa and Sharpe agar (HIMEDIA) medium (MRS). Ten grams of the sample was taken and homogenised with $90 \mathrm{ml}$ of sterile peptone water. The homogenate was diluted serially upto $10^{-8}$ and $1 \mathrm{ml}$ aliquot from $10^{-5}, 10^{-6}$ and $10^{-7}$ dilutions was used for isolation. The petriplates were incubated for 48 hours at $37^{\circ} \mathrm{C}$ anaerobically. After incubation, individual colonies were selected and transferred into sterile broths (MRS broth for enrichment). The bacteria from the enriched medium were purified using streak plate technique. Gram positive and catalase negative colonies were stored in glycerol solution at $-20^{\circ} \mathrm{C}$.

\section{Biochemical tests:}

Isolated bacteria were tested for Gram reaction, catalase production, spore formation and cell morphology according to the methods described by Kebede et al. (2007).

1. Gram staining- The Gram staining procedure was undertaken using crystal violet stain for one minute. The excess stain was removed under tap water. Again it was stained with Gram`s iodine as mordant for one minute and washed under tap water. The washed Gram`s iodine mordant was fixed with 5\% alcohol for 15 sec. and counterstained with safranine for $30 \mathrm{sec}$., washed under tap water and dried with cotton towel gently.

2. Catalase test- Catalase enzymes break down hydrogen peroxide into oxygen and water molecules and oxygen production was observed by the generation of bubbles. Catalase test was performed by adding few drops of $3 \%$ hydrogen peroxide to a test tube containing $24 \mathrm{~h}$ old culture of the isolate.

\section{Molecular Characterization \\ Genomic DNA isolation from bacteria:}

A single colony from an isolate was inoculated into $10 \mathrm{ml}$ of the MRS broth medium (kept in a $15 \mathrm{ml}$ Falcon tube) and incubated overnight at $37^{\circ} \mathrm{C}$. The cultivated culture was harvested by centrifugation at $5000 \mathrm{rpm}$ for $5 \mathrm{mins}$ and the genomic DNA was isolated by a genomic DNA isolation protocol (Sambrook and Russell, 2001).

\section{PCR, 16SrDNA sequencing and phylogenetic analysis:}

DNA was isolated from the culture. Its quality was evaluated on 1.0\% agarose gel; a single bond of high molecular weight DNA was observed. Fragment of 16SrDNA gene was amplified by $27 \mathrm{~F}$ and $1492 \mathrm{R}$ primers. A single discrete PCR amplicon bond of 1500 bp was observed when resolved on agarose gel. The PCR amplicon was purified to remove contaminants. Forward and reverse DNA sequencing reaction of PCR amplicon was carried out with forward and reverse primers using BDTv3.1 Cycle sequencing kit on ABI 3730x1 Genetic Analyser. Consensus sequence of 16SrDNA gene was generated from forward and reverse sequence data using aligner software. The 16SrDNA gene sequence was used to carry out BLAST with the database of NCBI genbank database. Based on maximum identity score first ten sequences were selected and aligned using multiple alignment software program Clustal W. Distance matrix was generated and the phylogenetic tree was developed using MEGA7. 


\section{Result and discussion:-}

Morphological and Biochemical properties:

Strains of bacteria isolated from chhenapoda (burnt sweet cheese) were examined. The bacterial isolates picked from MRS agar plates were found to belong to the genus Bacillus, according to their morphological and biochemical tests. The isolates were subjected to Gram staining test, endospore test and catalase test. It was inferred that the isolates were characterised as Gram positive, non spore forming and catalase negative (Table 1).

Table 1:-Characteristics of lactic acid bacteria isolated from chhenapoda.

\begin{tabular}{|l|l|l|}
\hline SERIAL NUMBER & CHARACTERIZATION & RESULT \\
\hline 1 & Cell Morphology & Rod shaped \\
\hline 2 & Gram Staining & Positive \\
\hline 3 & Endospore & Non spore forming \\
\hline 4 & Catalase & Negative \\
\hline
\end{tabular}

Microbial identification:

The isolate which was labelled as PD 13A was identified as Bacillus vallismortis based on nucleotide homology and phylogenetic analysis. g DNA and 16S amplicon QC data reflect the ladder specification (Fig. 1).

\section{gDNA}

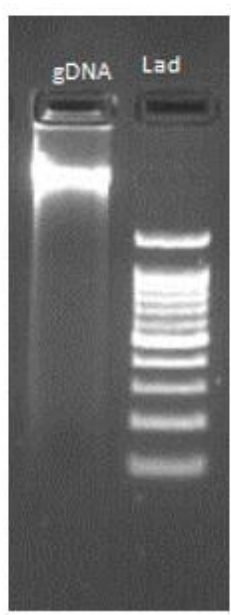

\section{S PCR amplicon}

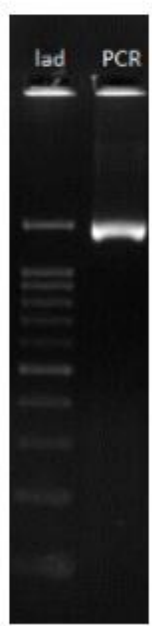

(bp)

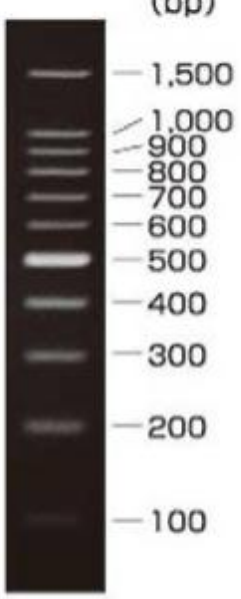

Fig.1:-Ladder specification

Sanger sequence chromatogram and the distribution of 100 BLAST hits on the query sequence were developed (Figs. 2 and 3).

\section{$>$ Forward Seq data}

GAGAATGCTAGTGTTAGGGGGTTTCCGCCCCTTAGTGCTGCAGCTAACGCATTAAGCACTCCGCCTGG GGAGTACGGTCGCAAGACTGAAACTCAAAGGAATTGACGGGGGCCCGCACAAGCGGTGGAGCATGT GGTTTAATTCGAAGCAACGCGAAGAACCTTACCAGGTCTTGACATCCTCTGACAATCCTAGAGATAG GACGTCCCCTTCGGGGGCAGAGTGACAGGTGGTGCATGGTTGTCGTCAGCTCGTGTCGTGAGATGTTG GGTTAAGTCCCGCAACGAGCGCAACCCTTGATCTTAGTTGCCAGCATTCAGTTGGGCACTCTAAGGTG ACTGCCGGTGACAAACCGGAGGAAGGTGGGGATGACGTCAAATCATCATGCCCCTTATGACCTGGGC TACACACGTGCTACAATGGACAGAACAAAGGGCAGCGAAACCGCGAGGTTAAGCCAATCCCACAAA TCTGTTCTCAGTTCGGATCGCAGTCTGCAACTCGACTGCGTGAAGCTGGAATCGCTAGTAATCGCGGA TCAGCATGCCGCGGTGAATACGTTCCCGGGCCTTGTACACACCGCCCGTCACACCACGAGAGTTTGTA ACACCCGAAGTCGGTGAGGTAACCTTTTAGGAGCCAGCCGCCGAAGGTGGGACAGATGATTGGGGTG AAGTCGTAACAGAGGTAACCGGC 
$>$ Reverse Seq Data

ATCCCAGGCGGAGTGCTTAATGCGTTAGCTGCAGCACTAAGGGGCGGAAACCCCCTAACACTTAGCA CTCATCGTTTACGGCGTGGACTACCAGGGTATCTAATCCTGTTCGCTCCCCACGCTTTCGCTCCTCAGC GTCAGTTACAGACCAGAGAGTCGCCTTCGCCACTGGTGTTCCTCCACATCTCTACGCATTTCACCGCT ACACGTGGAATTCCACTCTCCTCTTCTGCACTCAAGTTCCCCAGTTTCCAATGACCCTCCCCGGTTGAG CCGGGGGCTTTCACATCAGACTTAAGAAACCGCCTGCGAGCCCTTTACGCCCAATAATTCCGGACAA CGCTTGCCACCTACGTATTACCGCGGCTGCTGGCACGTAGTTAGCCGTGGCTTTCTGGTTAGGTACCG TCAAGGTGCCGCCCTATTTGAACGGCACTTGTTCTTCCCTAACAACAGAGCTTTACGATCCGAAAACC TTCATCACTCACGCGGCGTTGCTCCGTCAGACTTTCGTCCATTGCGGAAGATTCCCTACTGCT GCCTCC CGTAGGAGTCTGGGCCGTGTCTCAGTCCCAGTGTGGCCGATCACCCTCTCAGGTCGGCTACGCATCGT CGCCTTGGTGAGCCGTTACCTCACCAACTAGCTAATGCGCCGCGGGTCCATCTGTAAGTGGTAGCCGA AGCCACCTTTTATGTCTGAACCATGCGGTTCAGACAACCATCCGGTATTAGCCCCGGTTTCCCGGAGT TATCCCAGTCTTACAGGCAGGTTACCCACGTGTTACTCACCCGTCCGCCGCTAACATCAGGCAGCAAG CTCCCATCTGT

$>$ Reverse complement ACAGATGGGAGCTTGCTGCCTGATGTTAGCGGCGGACGGGTGAGTAACACGTGGGTAACCTGCCTGT AAGACTGGGATAACTCCGGGAAACCGGGGCTAATACCGGATGGTTGTCTGAACCGCATGGTTCAGAC ATAAAAGGTGGCTTCGGCTACCACTTACAGATGGACCCGCGGCGCATTAGCTAGTTGGTGAGGTAAC GGCTCACCAAGGCGACGATGCGTAGCCGACCTGAGAGGGTGATCGGCCACACTGGGACTGAGACAC GGCCCAGACTCCTACGGGAGGCAGCAGTAGGGAATCTTCCGCAATGGACGAAAGTCTGACGGAGCA ACGCCGCGTGAGTGATGAAGGTTTTCGGATCGTAAAGCTCTGTTGTTAGGGAAGAACAAGTGCCGTT CAAATAGGGCGGCACCTTGACGGTACCTAACCAGAAAGCCACGGCTAACTACGTGCCAGCAGCCGCG GTAATACGTAGGTGGCAAGCGTTGTCCGGAATTATTGGGCGTAAAGGGCTCGCAGGCGGTTTCTTAA GTCTGATGTGAAAGCCCCCGGCTCAACCGGGGAGGGTCATTGGAAACTGGGGAACTTGAGTGCAGAA GAGGAGAGTGGAATTCCACGTGTAGCGGTGAAATGCGTAGAGATGTGGAGGAACACCAGTGGCGAA GGCGACTCTCTGGTCTGTAACTGACGCTGAGGAGCGAAAGCGTGGGGAGCGAACAGGATTAGATACC CTGGTAGTCCACGCCGTAAACGATGAGTGCTAAGTGTTAGGGGGTTTCCGCCCCTTAGTGCTGCAGCT AACGCATTAAGCACTCCGCCTGGGAT

> PD_13_A consensus seq ACAGATGGGAGCTTGCTGCCTGATGTTAGCGGCGGACGGGTGAGTAACACGTGGGTAACCTGCCTGT AAGACTGGGATAACTCCGGGAAACCGGGGCTAATACCGGATGGTTGTCTGAACCGCATGGTTCAGAC ATAAAAGGTGGCTTCGGCTACCACTTACAGATGGACCCGCGGCGCATTAGCTAGTTGGTGAGGTAAC GGCTCACCAAGGCGACGATGCGTAGCCGACCTGAGAGGGTGATCGGCCACACTGGGACTGAGACAC GGCCCAGACTCCTACGGGAGGCAGCAGTAGGGAATCTTCCGCAATGGACGAAAGTCTGACGGAGCA ACGCCGCGTGAGTGATGAAGGTTTTCGGATCGTAAAGCTCTGTTGTTAGGGAAGAACAAGTGCCGTT CAAATAGGGCGGCACCTTGACGGTACCTAACCAGAAAGCCACGGCTAACTACGTGCCAGCAGCCGCG GTAATACGTAGGTGGCAAGCGTTGTCCGGAATTATTGGGCGTAAAGGGCTCGCAGGCGGTTTCTTAA

GTCTGATGTGAAAGCCCCCGGCTCAACCGGGGAGGGTCATTGGAAACTGGGGAACTTGAGTGCAGAA GAGGAGAGTGGAATTCCACGTGTAGCGGTGAAATGCGTAGAGATGTGGAGGAACACCAGTGGCGAA GGCGACTCTCTGGTCTGTAACTGACGCTGAGGAGCGAAAGCGTGGGGAGCGAACAGGATTAGATACC CTGGTAGTCCACGCCGTAAACGATGAGTGCTAAGTGTTAGGGGGTTTCCGCCCCTTAGTGCTGCAGCT AACGCATTAAGCACTCCGCCTGGGGAGTACGGTCGCAAGACTGAAACTCAAAGGAATTGACGGGGG CCCGCACAAGCGGTGGAGCATGTGGTTTAATTCGAAGCAACGCGAAGAACCTTACCAGGTCTTGACA TCCTCTGACAATCCTAGAGATAGGACGTCCCCTTCGGGGGCAGAGTGACAGGTGGTGCATGGTTGTC GTCAGCTCGTGTCGTGAGATGTTGGGTTAAGTCCCGCAACGAGCGCAACCCTTGATCTTAGTTGCCAG CATTCAGTTGGGCACTCTAAGGTGACTGCCGGTGACAAACCGGAGGAAGGTGGGGATGACGTCAAAT CATCATGCCCCTTATGACCTGGGCTACACACGTGCTACAATGGACAGAACAAAGGGCAGCGAAACCG CGAGGTTAAGCCAATCCCACAAATCTGTTCTCAGTTCGGATCGCAGTCTGCAACTCGACTGCGTGAAG CTGGAATCGCTAGTAATCGCGGATCAGCATGCCGCGGTGAATACGTTCCCGGGCCTTGTACACACCG CCCGTCACACCACGAGAGTTTGTAACACCCGAAGTCGGTGAGGTAACCTTTTAGGAGCCAGCCGCCG AAGGTGGGACAGATGATTGGGGTGAAGTCGTAACAGAGGTAACCGGC

Fig 2:-Sanger sequence chromatogram file data. 


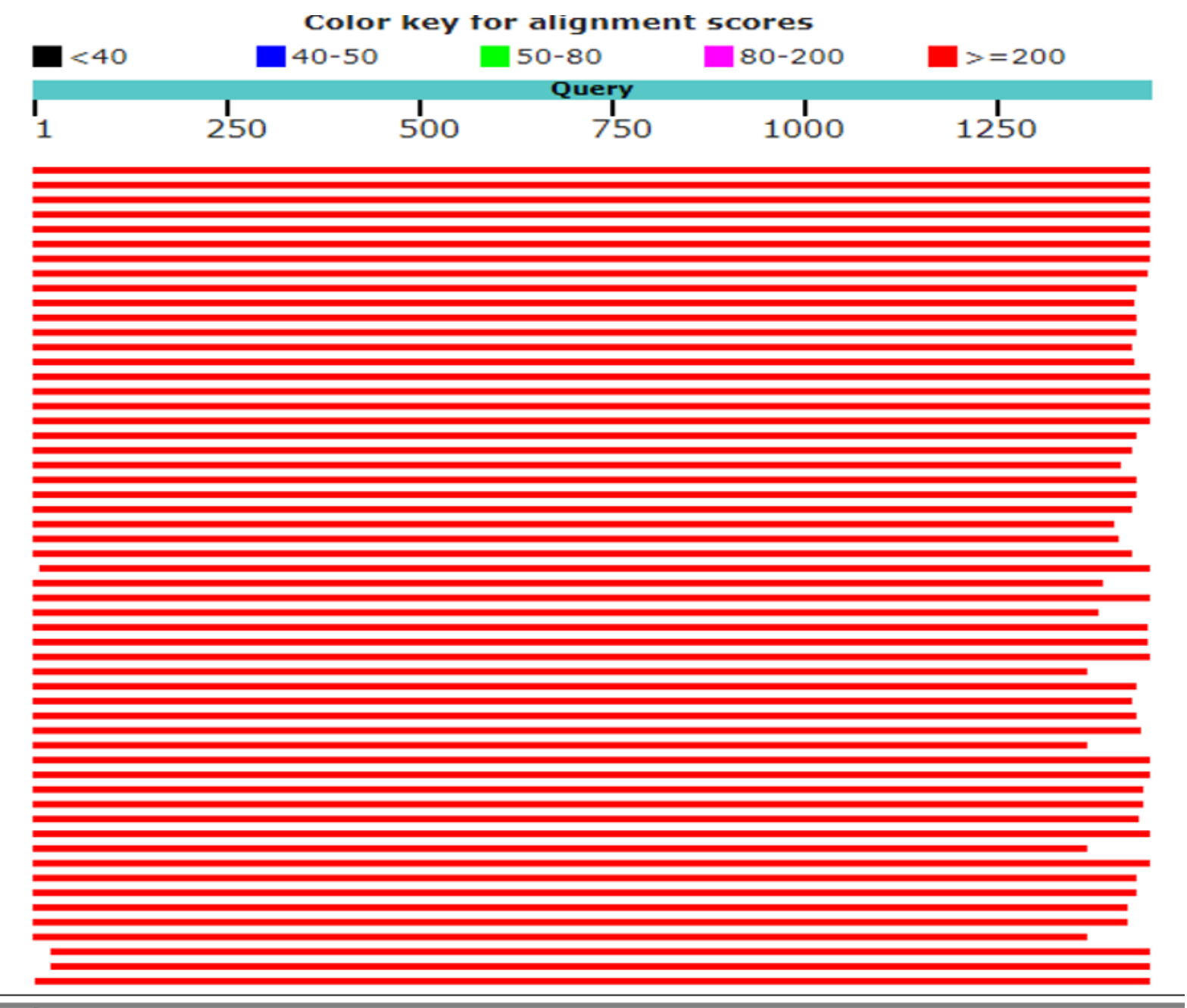

Fig 3:-Alignment view using combination of NCBI GenBank.

\begin{tabular}{|l|c|c|c|c|c|c|}
\hline \multicolumn{1}{|c|}{ Description } & $\begin{array}{c}\text { Max } \\
\text { score }\end{array}$ & $\begin{array}{c}\text { Total } \\
\text { score }\end{array}$ & $\begin{array}{c}\text { Query } \\
\text { cover }\end{array}$ & $\begin{array}{c}\text { E } \\
\text { value }\end{array}$ & Ident & Accession \\
\hline $\begin{array}{l}\text { Bacillus vallismortis strain DSM 11031 16S ribosomal RNA } \\
\text { gene, partial sequence }\end{array}$ & 2634 & 2634 & $99 \%$ & 0 & $99 \%$ & NR_024696.1 \\
\hline $\begin{array}{l}\text { Bacillus subtilis strain DSM 10 16S ribosomal RNA gene, } \\
\text { partial sequence }\end{array}$ & 2628 & 2628 & $99 \%$ & 0 & $99 \%$ & NR_027552.1 \\
\hline $\begin{array}{l}\text { Bacillus nematocida strain B-16 16S ribosomal RNA gene, } \\
\text { partial sequence }\end{array}$ & 2625 & 2625 & $99 \%$ & 0 & $99 \%$ & NR_115325.1 \\
\hline $\begin{array}{l}\text { Bacillus nakamurai strain NRRL B-41091 16S ribosomal } \\
\text { RNA, partial sequence }\end{array}$ & 2615 & 2615 & $99 \%$ & 0 & $99 \%$ & NR_151897.1 \\
\hline $\begin{array}{l}\text { Bacillus amyloliquefaciens strain NBRC 15535 16S } \\
\text { ribosomal RNA gene, partial sequence }\end{array}$ & 2615 & 2615 & $98 \%$ & 0 & $99 \%$ & NR_112685.1 \\
\hline $\begin{array}{l}\text { Bacillus amyloliquefaciens strain NBRC 15535 16S } \\
\text { ribosomal RNA gene, partial sequence }\end{array}$ & 2614 & 2614 & $98 \%$ & 0 & $99 \%$ & NR_041455.1 \\
\hline $\begin{array}{l}\text { Bacillus vallismortis strain NBRC 101236 16S ribosomal } \\
\text { RNA gene, partial sequence }\end{array}$ & 2610 & 2610 & $98 \%$ & 0 & $99 \%$ & NR_113994.1 \\
\hline $\begin{array}{l}\text { Bacillus subtilis strain NBRC 13719 16S ribosomal RNA } \\
\text { gene, partial sequence }\end{array}$ & 2608 & 2608 & $98 \%$ & 0 & $99 \%$ & NR_112629.1 \\
\hline $\begin{array}{l}\text { Bacillus amyloliquefaciens strain BCRC 11601 16S } \\
\text { ribosomal RNA gene, partial sequence }\end{array}$ & 2604 & 2604 & $98 \%$ & 0 & $99 \%$ & NR_116022.1 \\
\hline $\begin{array}{l}\text { Bacillus subtilis strain JCM 1465 16S ribosomal RNA gene, } \\
\text { partial sequence }\end{array}$ & 2603 & 2603 & $98 \%$ & 0 & $99 \%$ & NR_113265.1 \\
\hline
\end{tabular}

Table 2:-Significant alignments through sequencing (above). 
The evolutionary history was inferred by using the maximum likelihood method (Fig.4) based on the Kimura 2parameter model (Kimura, 1980). The bootstrap consensus tree inferred from 1000 replicates (Felsenstein, 1985) is taken to represent the evolutionary history of the taxa analysed (Felsenstein, 1985). Branches corresponding to partitions reproduced in less than $50 \%$ bootstrap replicates are collapsed. The percentage of replicate trees in which the associated taxa clustered together in the bootstrap test (1000 replicates) are shown next to the branches (Felsenstein, 1985). Initial tree (s) for the heuristic search were obtained automatically by applying Neighbour-Join and BioNJ algorithms to a matrix of pair- wise distances estimated using the Maximum Composite Liklihood (MCL) approach, and then selecting the topology with superior log likelihood value. The analysis involved 11 nucleotide sequences. Codon positions included were $1^{\text {st }}+2^{\text {nd }}+3^{\text {rd }}+$ Noncoding. All positions containing gaps and missing data were eliminated. There were a total of 1,434 positions in the final dataset. Evolutionary analysis were conducted in MEGA7 (Kumar et al., 2015).

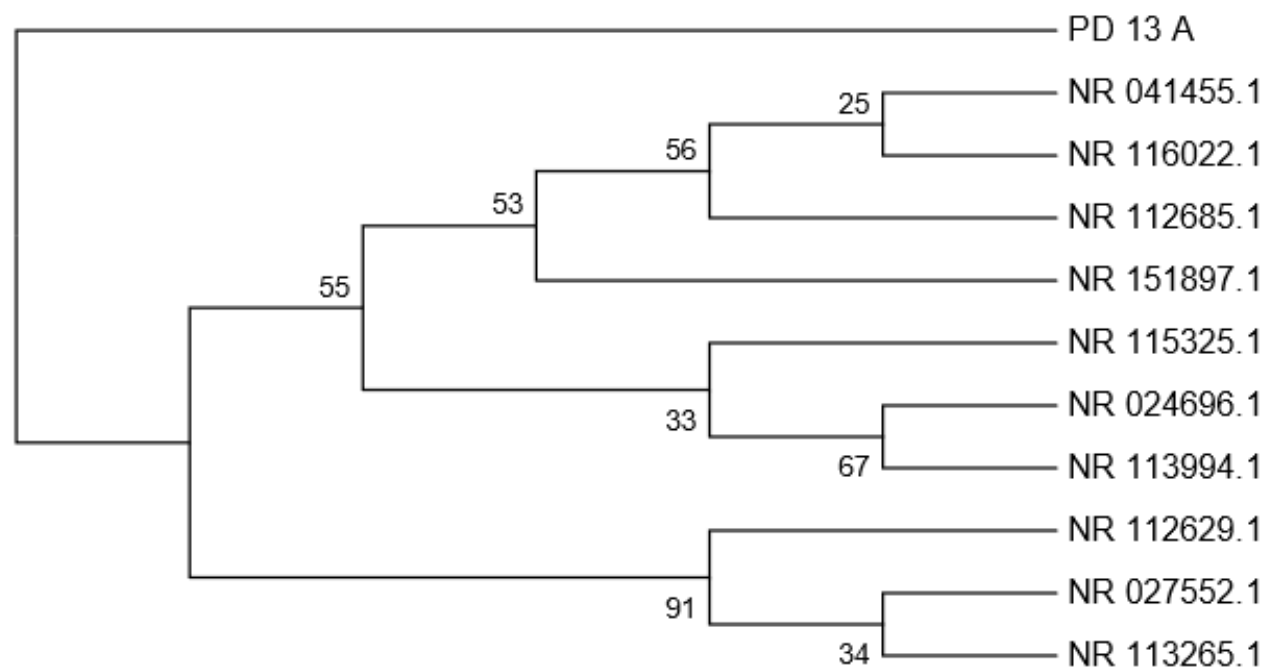

\section{Distance Matrix}

Fig 4:-Molecular phylogenetic analysis by maximum likelihood method.

Table 3:-Estimates of evolutionary divergence between sequences.

\begin{tabular}{|l|l|l|l|l|l|l|l|l|l|l|l|}
\hline PD_13_A & & 0.002 & 0.002 & 0.002 & 0.002 & 0.001 & 0.001 & 0.002 & 0.002 & 0.001 & 0.002 \\
\hline NR_024696.1 & 0.004 & & 0.002 & 0.001 & 0.001 & 0.001 & 0.001 & 0.000 & 0.002 & 0.001 & 0.002 \\
\hline NR_027552.1 & 0.004 & 0.003 & & 0.002 & 0.002 & 0.002 & 0.002 & 0.002 & 0.000 & 0.002 & 0.000 \\
\hline NR_115325.1 & 0.004 & 0.002 & 0.004 & & 0.001 & 0.001 & 0.001 & 0.001 & 0.002 & 0.001 & 0.002 \\
\hline NR_151897.1 & 0.005 & 0.003 & 0.004 & 0.004 & & 0.001 & 0.001 & 0.001 & 0.002 & 0.001 & 0.002 \\
\hline NR_112685.1 & 0.003 & 0.002 & 0.004 & 0.003 & 0.002 & & 0.000 & 0.001 & 0.002 & 0.000 & 0.002 \\
\hline NR_041455.1 & 0.003 & 0.002 & 0.004 & 0.003 & 0.002 & 0.000 & & 0.001 & 0.002 & 0.000 & 0.002 \\
\hline NR_113994.1 & 0.004 & 0.000 & 0.003 & 0.002 & 0.003 & 0.002 & 0.002 & & 0.002 & 0.001 & 0.002 \\
\hline NR_112629.1 & 0.004 & 0.003 & 0.000 & 0.004 & 0.004 & 0.004 & 0.004 & 0.003 & & 0.002 & 0.000 \\
\hline NR_116022.1 & 0.003 & 0.002 & 0.004 & 0.003 & 0.002 & 0.000 & 0.000 & 0.002 & 0.004 & & 0.002 \\
\hline NR_113265.1 & 0.004 & 0.003 & 0.000 & 0.004 & 0.004 & 0.004 & 0.004 & 0.003 & 0.000 & 0.004 & \\
\hline
\end{tabular}

The number of base substitutions per site between sequences is developed (Table3). Standard error estimate (s) is shown above the diagonal. Analyses were conducted using the Kimura 2- parameter model (Kimura, 1980) which involved 11 nucleotide sequences. Codon positions included were $1^{\text {st }}+2^{\text {nd }}+3^{\text {rd }}+$ Noncoding. All positions containing gaps and missing data were eliminated. There were a total of 1,434 positions in the final dataset. Evolutionary analyses were conducted in MEGA7 (Kumar et al., 2015).

\section{Conclusion:-}

Although molecular characterization of the lactic acid bacteria in different types of cheese has been completed, this finding focuses on the molecular characterization of the predominant LAB found in chhenapoda. This study 
concludes that Bacillus vallismortis is the predominant lactic acid bacteria which can be used to formulate the starter culture in the dairy industry for the commercial production of chhenapoda (burnt sweet cheese).

\section{References:-}

1. Angmo, K., Kumari, A., Savitri and Bhalla, T.C. (2016): Probiotic characterization of lactic acid bacteria isolated from fermented foods and beverage of Ladakh. LWT- Food Science and Technology, 66:428-435

2. Bozoudi, D., Kotzamanidis, C., Hatzikamari, M., Tzanetakis, N., Menexes,G. and Litopoulou- Tzanetaki,E. (2015): A comparison for acid production, proteolysis, autolysis and inhibitory properties of LAB from fresh and mature Feta PDO Greek cheese, made at three different mountainous areas. International Journal of Food Microbiology, 200:87-96

3. Bujnakova, D., Strakova, E. and Kmet, V. (2014): In vitro evaluation of the safety and probiotic properties of Lactobacilli isolated from chicken and calves. Anaerobe, 29:118-127

4. Cintas, L.M., Casaus, M.P., Herranz, C., Nes, I.F. and Hernandez, P.E. (2001): Review: Bacteriocins of Lactic Acid Bacteria. Food Science and Technology International, 7(4):281-305

5. Federici, S., Ciarrocchi, F., Campana, R., Ciandrini, E., Blasi, G. and Baffone, W. (2014): Identification and functional traits of LAB isolated from Ciauscolo salami produced in central Italy. Meat Science, 98(4):575-58

6. Felsenstein, J. (1985): Confidence limits on phylogenies: An approach using the bootstrap. Evolution, 39:783789

7. Fuller, R. (1989): Probiotics in man and animals. Journal of Applied Bacteriology, 66(5):365-378

8. Giraffa, G. (2003): Functionality of enterococci in dairy products. International Journal of Food Microbiology, 88(2-3):215-222

9. Junior, W.L.G. de Almeida, Ferrari, I.D.S., de Souza, J.V., da Silva, C.D.A., da Costa, M.M. and Dias, F.S. (2015): Characterization and evaluation of lactic acid bacteria isolated from goat milk. Food Control, 53:96-103

10. Kargozari, M., Emam-Djomeh, Z., Gandomi, H., Partovi, R., Ghasemlou, M. and Martin, R. (2015): Identification of selected lactobacillus strains isolated from Siahmazgi cheese and study on their behaviour after inoculation in fermented sausage model medium. LWT- Food Science and Technology, 62(2):1177-1183

11. Kebede, A., Viljoen, B., Gadaga, T., Narvhus, J. and Lourens- Hattingh, A. (2007): The effect of container type on the growth of yeast and lactic acid bacteria during production of Sethemi South African spontaneously fermented milk. Food Res. Int., 40:33-35

12. Kimura, M. (1980): A simple method for estimating evolutionary rate of base substitutions through comparative studies of nucleotide sequences. Journal of Molecular Evolution, 16:111-120

13. Kumar, A. and Kumar, D. (2015): Characterization of Lactobacillus isolated from dairy samples for probiotic properties. Anaerobe, 33:117-123

14. Kumar, S., Stecher, G. and Tamura, K. (2015) MEGA7: Molecular Evolutionary Genetic Analysis version 7.0 for bigger datasets. Molecular Biology and Evolution, (submitted)

15. Liong, M.T. and Shah, N.P. (2005): Bile salt deconjugation ability, bile salt hydrolase activity and cholesterol coprecipitation ability of Lactobacilli strains. International Dairy Journal, 15(4):391-398

16. Lu, X., Yi, L., Dang, J., Dang, Y. and Liu, B. (2014): Purification of novel bacteriocin produced by Lactobacillus coryniformis MXJ32 for inhibiting bacterial foodborne pathogens including antibiotic resistant microorganisms. Food Control, 46:264-271

17. Mercenier, A., Pavan, S. and Pot, B. (2003): Probiotics as biotherapeutic agents: Present knowledge and future prospects. Current Pharmaceutical Design, 9(2):175-191

18. Ouwehand, A.C., Salminen, S., Isolauri, E. (2002): Probiotics: an overview of beneficial effects. Antonie Van Leewenhoek- Journal of Microbiology, 82(1-4):279-289

19. Palomo, M., Gutierrez, A.M., Perez-Conde, M.C., Camara, C. and Madrid, Y. (2014): Se metallomics during lactic fermentation of Se-enriched yogurt. Food Chemistry, 164:371-379

20. Reale, A., Di Renzo, T., Rossi, F. et al., (2015): Tolerance of Lactobacillus casei, Lactobacillus paracasei and Lactobacillus rhamnosus strains to stress factors encountered in food processing and in the gastrointestinal tract. LWT- Food Science and Technology, 60(2):721-728

21. Sambrook, J. and Russel, J. (2001): Molecular cloning. A laboratory Manual, Cold Spring Harbour Laboratory, New York

22. Strompfova, V. and Laukova, A. (2014): Isolation and characterization of faecal Bifidobacteria and lactobacilli isolated from dogs and primates. Anaerobe, 29:108-112

23. Sullivan, L.O', Ross, R.P. and Hill, C. (2002): Potential of bacteriocin-producing lactic acid bacteria for improvements in food safety and quality. Biochimie, 84(5-6):593-604 
24. Tabanelli, G., Montanari, C., Bargossi, E. et al., (2014): Control of tyramine and histamine accumulation by LAB using bacteriocin forming lactococci. International Journal of Food Microbiology, 190:14-23

25. Todorov, S.D. and de Melo Franco, B.D.G., (2010): Lactobacillus plantarum: Characterization of the species and application in food production. Food Reviews International, 26(3):205-229

26. Tserovska, L., Stefanova, S. and Yordanova, T. (2002): Identification of lactic acid bacteria isolated from Katyk, goat's milk and cheese. Journal of Culture Collections, 3:48-52. 